\title{
PROPRIEDADES FÍSICO-MECÂNICAS DO LENHO DETERIORADO POR FUNGOS APODRECEDORES DE ÁRVORES DE Tipuana tipu
}

\author{
Sergio Brazolin ${ }^{1 *}$, Mario Tomazello Filho², Takashi Yojo ${ }^{1}$, Mário Albino de Oliveira Netoํ․ Álisson Rangel \\ Albuquerque $^{3}$, Carlos Roberto Sette Júnior ${ }^{4}$
}

*Autor para correspondência: brazolin@ipt.br

\begin{abstract}
RESUMO: A tipuana (Tipuana tipu) foi muito utilizada na arborização urbana. De maneira geral, o manejo inadequado expõe o lenho à ação dos fungos e insetos xilófagos, muitas vezes associados à queda da árvore. Portanto, com este trabalho, objetivou-se caracterizar as propriedades físico-mecânicas do lenho sadio e biodeteriorado por fungos apodrecedores em árvores de tipuana da arborização urbana da cidade de São Paulo-SP. Treze árvores com deterioração no lenho foram suprimidas. Da base do tronco foram cortados toretes de $1 \mathrm{~m}$ de comprimento para a caracterização das propriedades físico-mecânicas dos lenhos sadio e deteriorado. Os resultados indicaram que, por meio do perfil radial de densidade por densitometria de raios X, foram identificados sete padrões de biodeterioração do lenho, sendo, (EXS) com acúmulo de extrativos e sadio, (ZR) com zona de reação e sadio, (NS) normal e sadio, $\left(\mathrm{PB}_{\mathrm{INC}} ; \mathrm{PB}_{\mathrm{INT}}\right)$ podridão branca incipiente ou intensa e $\left(\mathrm{PM}_{\mathrm{INC}} ; \mathrm{PM}_{\mathrm{INT}}\right)$ podridão mole incipiente ou intensa, com densidades 0,94 , $0,92,0,82,0,66,0,41,0,67$ e 0,44 g. $\mathrm{cm}^{-3}$, respectivamente. Os ensaios mecânicos evidenciaram os lenhos (ZR) (EXS) com os maiores valores de resistência e rigidez de 84 e $80 \mathrm{MPa}$ e 6461 e $5826 \mathrm{MPa}$, respectivamente; o lenho (NS) apresentou valores de 62 e 4642 $\mathrm{MPa}$ e os padrões $\left(\mathrm{PB}_{\mathrm{INC}}\right)\left(\mathrm{PM}_{\mathrm{INT}}\right)$ os menores e significativos valores de resistência e rigidez, destacando o (PB $\left.{ }_{\mathrm{INT}}\right)$ com valores de 5 e $571 \mathrm{MPa}$. A redução dos valores de densidade, resistência e rigidez do lenho esteve relacionada com a biodeterioração da parede celular das células das árvores de tipuana pelos fungos apodrecedores.
\end{abstract}

Palavras-chave: densitometria de raios X, propriedades físicas e mecânicas, podridão branca, podridão mole.

\section{MECHANICAL AND PHYSICAL PROPERTIES OF Tipuana tipu WOOD DETERIORATED BY DECAYING FUNGI}

\begin{abstract}
The tipuana was widely used in urban arborization. In general, inadequate management exposes the wood to the action of wood decaying fungi and insects, often associated with the fall of the trees. The aim of this study was to evaluate the physical and mechanical properties of sound and rotten tipuana wood from São Paulo City's afforestation. Thirteen old trees with symptoms of wood deterioration were removed. From the basal region of the trunk were cut 1 m-length stem segments, to characterize the physical and mechanical properties of sound and decayed wood. The results indicated that through the radial wood density profile by X-ray densitometry were classified seven pattern of wood biodeterioration, named (EXS) with accumulation of extractives and sound, (ZR) with the reaction zone and sound, (NS) normal and sound, $\left(P B_{I N C} ; P B_{I N T}\right)$ incipient and intense white rot (PM $\left(P M_{I N C}\right)$ incipient

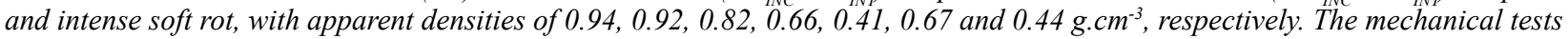
showed that wood classified as (ZR) (EXS) presented the highest values of strength and stiffness of 84 and $80 \mathrm{MPa}$ and $6461 \mathrm{MPa}$ and 5826, respectively; the (NS) showed values of 62 and $4642 \mathrm{MPa}$, and the $\left(P B_{I N C}\right)\left(P M_{I N T}\right)$ the significant and lowest values of strength and stiffness, enhancing $\left(P B_{I N T}\right)$ with values of 5 and $571 \mathrm{MPa}$. The reduction of density, strength and stiffness of wood is related to the biodeterioration of wood cell walls of trees tipuana by decaying fungi
\end{abstract}

Keywords: X-ray densitometry, physical and mechanicals properties, white rot, soft rot.

\section{INTRODUÇÃO}

As árvores de Tipuana tipu (tipuana) constituem parte integrante e característica da paisagem urbana de inúmeros bairros de São Paulo e de outras cidades brasileiras. Pelo crescimento e dimensões das árvores, quando adultas, características do tronco e da casca, forma e adensamento da copa e floração atrativa, foram extensivamente utilizadas na arborização urbana dos passeios públicos e praças, da cidade de São Paulo, há cerca de 60-70 anos.

As tipuanas, em ambiente urbano, têm, de modo geral, o desenvolvimento e sobrevivência afetados pelo manejo inadequado (poda aérea e do sistema radicular,

1 Instituto de Pesquisas Tecnológicas do Estado de São Paulo S.A. - São Paulo, São Paulo, Brasil

2 Universidade de São Paulo - Piracicaba, São Paulo, Brasil

3 Universidade Federal de Goiás - Goiânia, Goiás, Brasil

4 Universidade Federal de Goiás - Goiânia, Goiás, Brasil

Cerne, Lavras, v. 20, n. 2, p. 183-190, abr./jun. 2014 
impermeabilização e compactação do solo, abertura de valas para instalação de tubulações e reparos e instalação de equipamentos urbanos), estresse climático pela temperatura elevada (ilhas de calor), poluição ambiental e fatores relacionados.

Nessas condições, as árvores ficam sujeitas às injúrias, seguindo-se a biodeterioração do lenho por microrganismos xilófagos, cupins e brocas da madeira causando, em muitos casos, a sua queda ou morte (COSTALEONARDO, 2002; TOLEDO; ROMAGNANO, 2006). Nesse contexto, a avaliação das alterações das propriedades físico-mecânicas do lenho sadio e deteriorado das árvores urbanas é necessária para a compreensão do processo de biodeterioração e das forças de tensão de ruptura do tronco aos esforços externos, permitindo melhor definição de critérios para predição do seu risco de ruptura e de queda.

Pelo exposto, neste trabalho, objetivou-se caracterizar as propriedades físico-mecânicas do lenho sadio e biodeteriorado por fungos apodrecedores em árvores de Tipuana tipu (tipuana) da arborização urbana da cidade de São Paulo-SP.

\section{MATERIAL E MÉTODOS}

\section{1 Área experimental}

As árvores de tipuana selecionadas no presente trabalho estavam plantadas em sete regiões da área urbana da cidade de São Paulo (Cerqueira César, Pacaembu-Sumaré, Alto de Pinheiros, Alto da Lapa, Vila Nova Conceição, Paraíso e Alto da Boa Vista). Essas regiões foram indicadas pela Secretaria do Verde e do Meio Ambiente de São Paulo (SVMA), pela elevada ocorrência de árvores de tipuana longevas, com sintomas de deterioração do lenho e com elevada infestação por cupins subterrâneos (BRAZOLIN et al., 2006; ROMAGNANO, 2004). O clima é classificado como subtropical, com valores médios anuais de temperatura, umidade relativa do ar (UR) e precipitação pluviométrica de $19{ }^{\circ} \mathrm{C}, 78 \%$ e $128,3 \mathrm{~mm}$, respectivamente (SÃO PAULO, 2004).

\subsection{Amostragem do lenho de tipuana}

Foram coletadas amostras do lenho de 13 árvores de tipuana localizadas nos bairros compreendidos pela área experimental e que foram suprimidas pela Prefeitura Municipal de São Paulo, em função de queda por fortes ventos e chuva, período de 2005 a 2008. Dessas árvores, foram cortados os toretes basais do tronco, com o comprimento de $1 \mathrm{~m}$, transportados para o Laboratório de Preservação de Madeira e Biodeterioração de Materiais (LPB) do Instituto de Pesquisas Tecnológicas do Estado de São Paulo (IPT). Na superfície do lenho, foi aplicada solução de ácido bórico $3 \%$, para evitar o desenvolvimento de fungos emboloradores e manchadores e armazenados em ambiente seco e sobre esteios para evitar o contato com o piso.

\subsection{Caracterização das propriedades físico-mecânicas do lenho sadio e deteriorado}

Os padrões de lenho sadio e deteriorado das árvores de tipuana pelos fungos apodrecedores foram caracterizados pela determinação da densidade aparente pela metodologia de densitometria de raios X e pela avaliação da sua tensão de ruptura à flexão estática ou módulo de ruptura. A confirmação da deterioração do lenho e do tipo de apodrecimento foi feita por meio da análise de lâminas histológicas obtidas segundo método proposto por Brazolin (2009).

\subsubsection{Perfil radial da densidade aparente do lenho por densitometria de raios $X$}

Dos segmentos basais do tronco das árvores de tipuana foram cortadas sub-amostras $(20 \times 10 \mathrm{~mm}$, altura e espessura), fixadas em suporte de madeira e seccionadas no sentido transversal (1x10 mm, espessura e altura) em aparelho de dupla serra circular. As amostras foram acondicionadas em sala climatizada $\left(12 \mathrm{~h} ; 20^{\circ} \mathrm{C} ; 50 \%\right.$ UR $)$ atingindo $10 \%$ umidade.

Após climatização, foram dispostas e radiografadas sobre filmes de raios $\mathrm{X}$ em equipamento Hewlett Packard, Faxitron 43805 N. As radiografias do lenho foram reveladas e obtidas imagens digitais em scanner com resolução de 1000 dpi e analisadas nos programas CRAD e CERD (AMARAL; TOMAZELLO-FILHO, 1998; TOMAZELLO-FILHO et al., 2008). Para cada amostra, foi determinado o respectivo perfil radial de densidade aparente do lenho (base massa/volume a 10\%), possibilitando caracterizar as regiões sadias e afetadas por fungos xilófagos e demarcar e cortar os corpos de prova para a determinação do módulo de ruptura e módulo de elasticidade à flexão estática.

Cerne, Lavras, v. 20, n. 2, p. 183-190, abr./jun. 2014 


\subsubsection{Módulos de ruptura e de elasticidade do lenho}

Os corpos de prova $(5 \times 5 \times 75 \mathrm{~mm})$ foram utilizados para a determinação da densidade aparente pelo método hidrostático com mercúrio, conforme descrito pela American Society of Testing Materials - ASTM D-2395 (AMERICAN SOCIETY OF TESTING MATERIALS ASTM, 2002) e avaliados quanto ao módulo de ruptura e módulo de elasticidade à flexão estática paralela às fibras, com esforço aplicado na direção radial, segundo método adaptado da Norma Brasileira Regulamentadora - NBR 7190 da Associação Brasileira de Normas Técnicas - ABNT (1997). No ensaio estático, os corpos de prova foram apoiados em vão livre de $60 \mathrm{~mm}$, mantendo-se uma relação de 12 para 1 entre o vão e a altura do corpo de prova e aplicada força no meio do vão livre. Foram registradas, simultaneamente, a flecha e a força até a ruptura dos corpos de prova ou a carga máxima para a determinação do valor máximo de tensão normal sob flexão ou módulo de ruptura e do valor do módulo de elasticidade. O modelo de falha (fratura) dos corpos de prova do lenho sadio e apodrecido por fungos foi avaliado segundo Bodig e Jayne (1992).

\subsection{Análise estatística}

A análise da variância de Kruskal-Walis foi aplicada para as análises das propriedades físico-mecânicas dos lenhos sadios e afetados por fungos apodrecedores. $\mathrm{O}$ teste de Mann-Whitney foi utilizado para a comparação das médias dos tratamentos em nível de 5\% de significância.

\section{RESULTADOS}

\subsection{Densidade aparente do lenho por densitometria de raios $X$}

Os perfis radiais de densidade aparente do lenho de tipuana e os respectivos valores médios, obtidos por densitometria de raios $\mathrm{X}$, permitiram classificar sete padrões de biodeterioração (Tabela 1; Figura 1), sendo:

1) normal e sadio (NS) - lenho claro, com coloração branco-amarelada, camadas de crescimento evidentes e sem sintoma de ataque de fungos (Figuras 1 A-D);

2) com acúmulo de extrativos e sadio (EXS) lenho claro, com evidente coloração amarelada, formato e tamanho irregulares, camadas de crescimento perceptíveis, sem sintoma de ataque de fungos e com densidade aparente, normalmente superior ao lenho normal sadio (Figura 1B);

3) com zona de reação e sadio (ZR) - lenho escuro, com coloração avermelhada, causada pela deposição de extrativos nas células, formato e tamanho irregulares, camadas de crescimento ainda perceptíveis, delimitando os lenhos normal e sadio do biodeteriorado (mecanismo de resistência) e com densidade aparente, normalmente superior ao padrão de lenho normais e sadios. As linhas de compartimentalização (LC) no lenho de tipuana, características do mecanismo de resistência aos organismos xilófagos, com densidade aparente nitidamente superior são, também, indicadas na secção transversal das amostras do lenho (Figura 1A);

Tabela 1 - Densidade aparente média do lenho de tipuana, por padrões de biodeterioração.

Table 1 - Average specific gravity of tipuana wood, by patterns of biodeterioration.

\begin{tabular}{cc}
\hline $\begin{array}{c}\text { Padrão de } \\
\text { Biodeterioração }\end{array}$ & Densidade aparente $\left({\left.\mathrm{g} \cdot \mathrm{cm}^{-3}\right)}^{*}\right.$ \\
\hline EXS & $0,94 \pm 0,16 \mathrm{a}$ \\
$\mathrm{ZR}$ & $0,92 \pm 0,15 \mathrm{ab}$ \\
$\mathrm{NS}$ & $0,82 \pm 0,08 \mathrm{~b}$ \\
$\mathrm{~PB}_{\mathrm{INC}}$ & $0,66 \pm 0,08 \mathrm{c}$ \\
$\mathrm{PM}_{\mathrm{INC}}$ & $0,67 \pm 0,04 \mathrm{c}$ \\
$\mathrm{PB}_{\mathrm{INT}}$ & $0,41 \pm 0,09 \mathrm{~d}$ \\
$\mathrm{PM}_{\mathrm{INT}}$ & $0,44 \pm 0,13 \mathrm{~d}$ \\
\hline
\end{tabular}

Kruskal-Walis: $\mathrm{X}^{2}=58,26$; $\mathrm{p}<0,05$; letras diferentes são estatisticamente significantes.

*EXS: com acúmulo de extrativos, ZR: com zona de reação e sadio, NS: normal e sadio, $\mathrm{PB}_{\mathrm{INC}}$ : com podridão branca incipiente, $\mathrm{PM}_{\mathrm{INC}}$ : com podridão mole incipiente, $\mathrm{PB}_{\mathrm{INT}}$ : com podridão branca intensa, $\mathrm{PM}_{\mathrm{INT}}$ :com podridão mole intensa.

4) com podridão mole incipiente $\left(\mathrm{PM}_{\mathrm{INC}}\right)$ - lenho com descoloração escura e parda, formato e tamanho irregulares, diminuição pouco acentuada da densidade aparente do lenho em relação ao normal-sadio e sem evidências macroscópicas de redução das propriedades mecânicas (Figura 1B);

5) com podridão mole intensa $\left(\mathrm{PM}_{\mathrm{INT}}\right)$ - lenho com descoloração escura e parda, formato e tamanho irregulares, camadas de crescimento do lenho não perceptíveis, friável, com perda de resistência mecânica e redução acentuada da densidade aparente do lenho (Figura 1B);

6) com podridão branca incipiente $\left(\mathrm{PB}_{\mathrm{INC}}\right)$ - lenho com descoloração esbranquiçada, formato e tamanho

Cerne, Lavras, v. 20, n. 2, p. 183-190, abr./jun. 2014 
irregulares, camadas de crescimento ainda perceptíveis, pequena redução da densidade aparente do lenho em relação ao normal-sadio, sem mostrar evidências macroscópicas de redução das propriedades mecânicas e linhas escuras e finas de consolidação e compartimentalização do fungo, pela formação de placa pseudoesclerotial (Figura 1C);

7) com podridão branca intensa $\left(\mathrm{PB}_{\mathrm{INT}}\right)$ - lenho com descoloração esbranquiçada, formato e tamanho irregulares, camadas de crescimento do lenho não perceptíveis, aspecto esponjoso em consequência do desfibrilamento do lenho, perda de resistência mecânica e redução acentuada da densidade aparente do lenho (Figura 1D).

O lenho de tipuana nos padrões de biodeterioração se caracterizou pela oscilação no perfil radial de densidade aparente e mostrou diferenças significativas para o método de densitometria de raios $X$ (Figura 1).

Os lenhos sadios (NS, EXS, ZR) diferiram do lenho com podridão branca ou mole no estágio incipiente e intenso, sendo que o lenho extrativo/sadio (EXS) de maior valor médio, diferiu do lenho normal/sadio (NS) e do lenho com zona de reação $(\mathrm{ZR})$, este último pode ser considerado um padrão
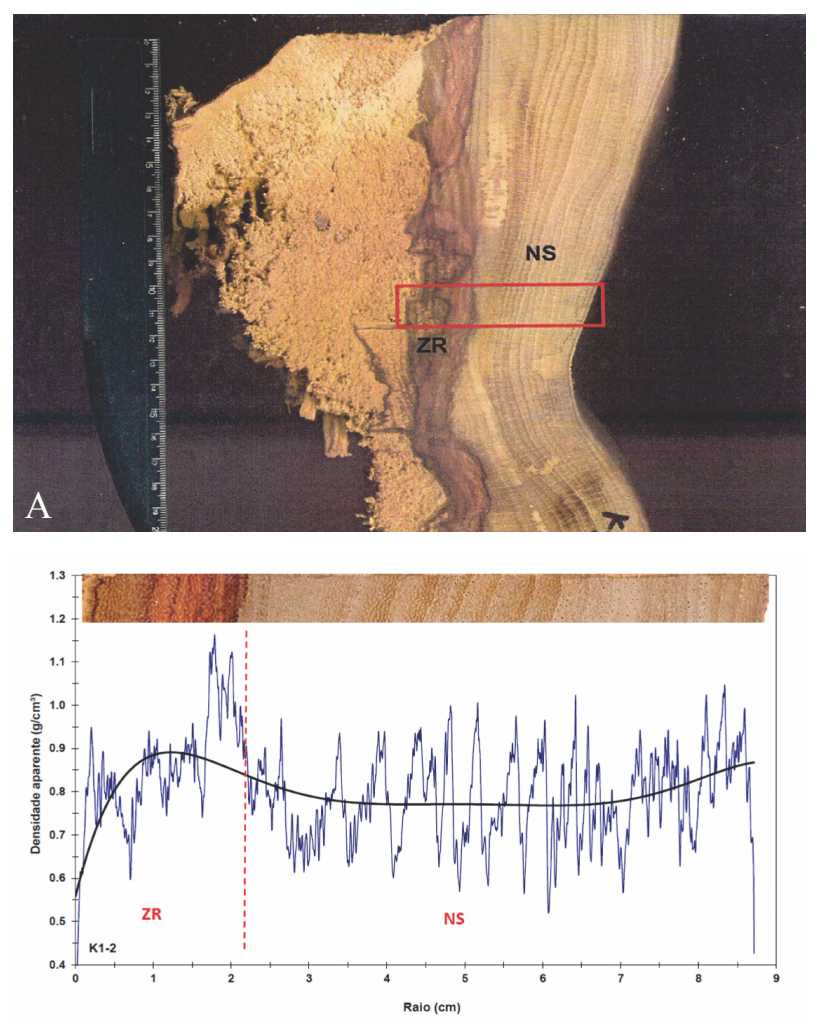

Cerne, Lavras, v. 20, n. 2, p. 183-190, abr./jun. 2014 intermediário. Os maiores valores de densidade aparente para os lenhos EXS e ZR, 0,94 e 0,92 g.cm ${ }^{-3}$ respectivamente, estão relacionados com presença de extrativos depositados no lume e na parede das células que, da mesma forma, restringem o desenvolvimento de microrganismos xilófagos (BRAZOLIN, 2009). O lenho normal e sadio (NS) apresentou densidade aparente média de $0,82{\mathrm{~g} . \mathrm{cm}^{-3}}^{-}$, sendo de valor superior ao reportado por Brazolin (2009) e Mainieri e Chimelo (1989) que foi de $0,63 \mathrm{~g} . \mathrm{cm}^{-3}$. Essa diferença de valores pode ser explicada pelos diferentes métodos de medição da densidade aparente da madeira utilizados (BRAZOLIN, 2009; BUCUR et al., 1997).

A redução da densidade aparente do lenho causada pelos fungos de podridão branca e mole foi notado, diferindo entre si e caracterizando-os como estágios de deterioração inicial ou incipiente da parede celular $\left(\mathrm{PB}_{\mathrm{INC}}\right.$ e $\left.\mathrm{PM}_{\mathrm{INC}}\right) \mathrm{e}$ intenso $\left(\mathrm{PB}_{\mathrm{INT}}\right.$ e $\left.\mathrm{PM}_{\mathrm{INT}}\right)$. Para cada estágio de apodrecimento do lenho (inicial e intenso), o ataque de fungos de podridão mole e branca não diferiu significativamente pela técnica de densitometria de raios $\mathrm{X}$.

Os resultados evidenciaram a importância e aplicabilidade da densitometria de raios $\mathrm{X}$ no estudo e
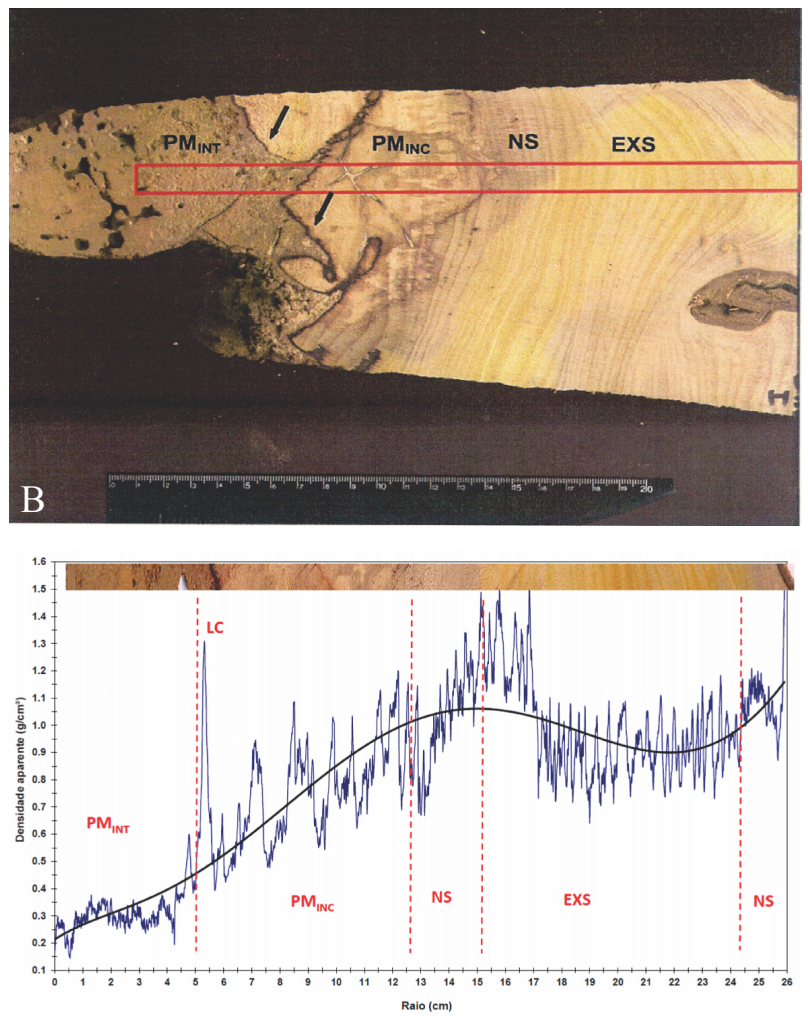

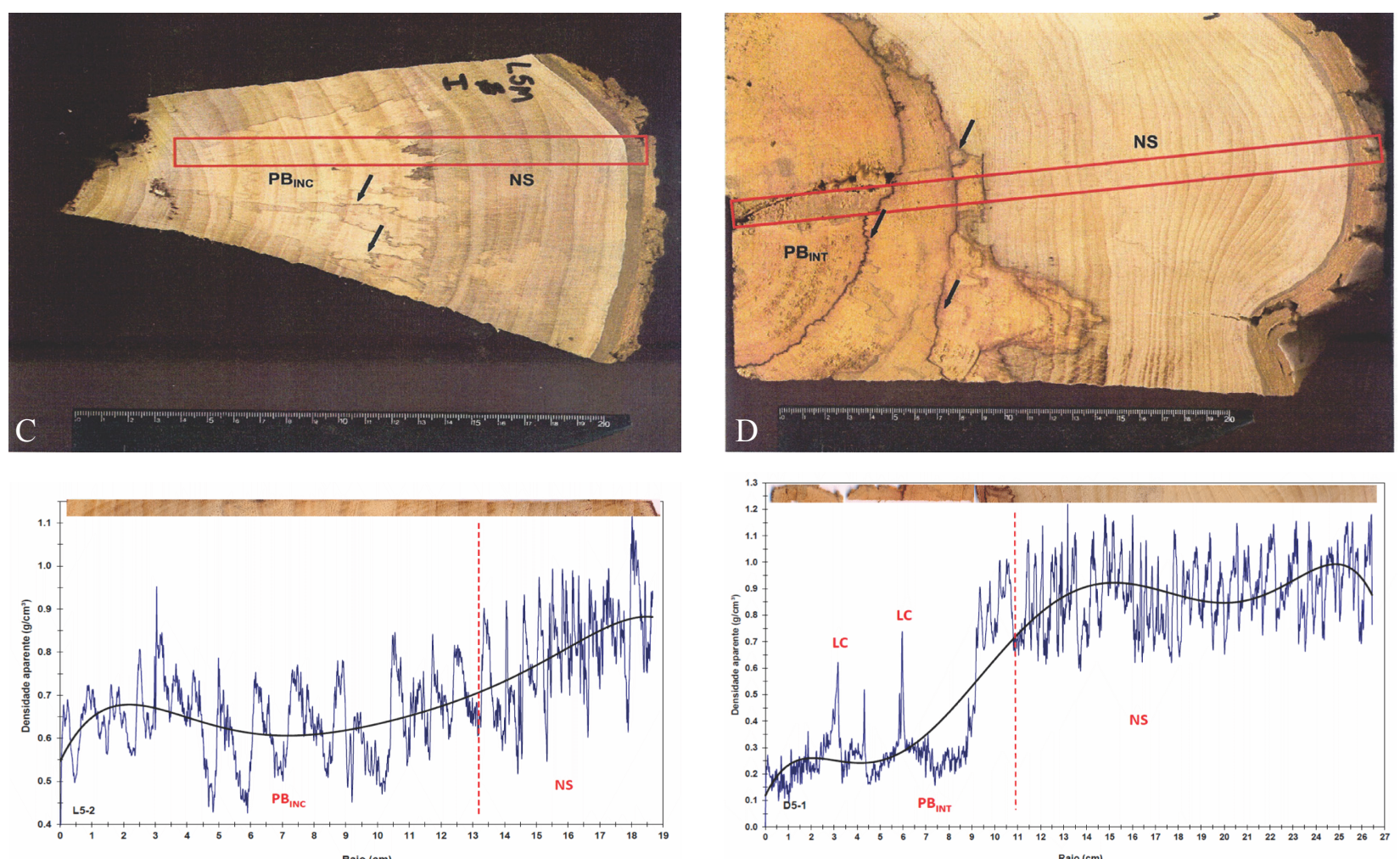

Figura 1 - Seção transversal do lenho de tipuana evidenciando diferentes padrões de biodeterioração do lenho e respectivos perfis radiais de densidade: A- com lenho normal-sadio (NS) e de zona de reação-sadio (ZR); B- normal-sadio (NS) com extrativo e sadio (EXS); podridão mole incipiente $\left(\mathrm{PM}_{\mathrm{INC}}\right)$; podridão mole intensa $\left(\mathrm{PM}_{\mathrm{INT}}\right)$. C- normal-sadio (NS) e com podridão branca incipiente $\left(\mathrm{PB}_{\mathrm{INC}}\right)$, setas indicam a linha de compartimentalização do fungo com a formação de placa pseudoesclerotial; D - normal-sadio (NS) e com podridão branca intensa $\left(\mathrm{PB}_{\mathrm{INT}}\right)$ e setas indicando a linha de compartimentalização.

Figure 1 - Transversal section of wood from tipuana trees showing different patterns of biodeterioration and their radial density profiles: A-normal-sound (NS) and the reaction zone-sound (ZR); B-normal-sound (NS) with extractives and sound (EXS) and incipient soft $\operatorname{rot}\left(P M_{I N C}\right)$; intense soft rot $\left(P M_{I N T}\right)$. C-normal-sound (NS) and incipient white rot $\left(P B_{I N C}\right)$, arrows indicate the line of compartmentalization of the fungus with formation of pseudoesclerotial plaque; $D$ - normal-sound (NS) and with intense white rot $\left(P B_{I N T}\right)$ and arrows indicating the line of compartmentalization.

caracterização do lenho das árvores urbanas, possibilitando a diferenciação das regiões de lenho sadio-biodeteriorado, definindo o seu estado de sanidade e fornecendo o diagnóstico preciso para a sua manutenção ou supressão. Neste sentido, Macchioni et al. (2007) e Tomazello-Filho et al. (2008) sugeriram, também, a aplicação dessa técnica na avaliação expedita da durabilidade natural do lenho em ensaios laboratoriais e de campo.

\subsection{Módulos de ruptura e de elasticidade do lenho}

Os valores do módulo de ruptura e do módulo de elasticidade à flexão estática no sentido radial do lenho dos padrões de biodeterioração (Tabela 2), obtidos por meio da densitometria de raios $\mathrm{X}$, reduziram-se significativamente com o aumento do grau de biodeterioração do lenho por fungos de podridão branca ou mole.

No lenho com zona de reação e sadio (ZR) e com acúmulo de extrativos (EXS), observaram-se os maiores valores de módulo de ruptura e módulo de elasticidade, 84 e $80 \mathrm{MPa}$ e 6461 e $5826 \mathrm{MPa}$, respectivamente, em comparação ao lenho constituído por células normaissadias (lenho NS). Os valores observados para os dois padrões de biodeterioração mostram relação com a elevada densidade aparente do lenho (Tabela 1) pelos extrativos

Cerne, Lavras, v. 20, n. 2, p. 183-190, abr./jun. 2014 
Tabela 2 - Módulo de ruptura e módulo de elasticidade do lenho de tipuana em diferentes padrões de biodeterioração.

Table 2 - Modulus of rupture and elasticity modulus of tipuana's wood in different patterns of biodeterioration.

\begin{tabular}{ccccc}
\hline $\begin{array}{c}\text { Padrão de biodeterioração } \\
\text { do lenho }\end{array}$ & $\begin{array}{c}\mathrm{N}^{\circ} \text {. de amostras } \\
\text { do lenho }\end{array}$ & $\begin{array}{c}\text { Módulo de ruptura }\left(^{*}\right) \\
(\mathrm{MPa})\end{array}$ & $\begin{array}{c}\text { Módulo de elasticidade }\left(^{* *}\right) \\
(\mathrm{MPa})\end{array}$ & $\begin{array}{c}\text { Densidade aparente }\left(^{* * *}\right) \\
\left(\mathrm{g} \cdot \mathrm{cm}^{-}\right)\end{array}$ \\
\hline ZR & 19 & $83,84 \pm 11,77 \mathrm{a}$ & $6461,16 \pm 781,27$ a & $0,651 \pm 0,062$ \\
EXS & 35 & $79,57 \pm 15,32 \mathrm{a}$ & $5825,55 \pm 1469,65 \mathrm{~b}$ & $0,676 \pm 0,049$ \\
$\mathrm{NS}$ & 35 & $62,00 \pm 14,00 \mathrm{~b}$ & $4641,67 \pm 1014,43 \mathrm{c}$ & $0,601 \pm 0,091$ \\
$\mathrm{PM}_{\mathrm{INC}}$ & $(* * * *$ & - & - & - \\
$\mathrm{PB}_{\mathrm{INC}}$ & 16 & $28,03 \pm 6,39 \mathrm{c}$ & $2245,19 \pm 522,09 \mathrm{~d}$ & $0,510 \pm 0,049$ \\
$\mathrm{PM}_{\mathrm{INT}}$ & 10 & $12,99 \pm 7,20 \mathrm{~d}$ & $1054,12 \pm 473,90 \mathrm{e}$ & $0,300 \pm 0,062$ \\
$\mathrm{~PB}_{\mathrm{INT}}$ & 34 & $4,66 \pm 3,45 \mathrm{e}$ & $571,55 \pm 404,40 \mathrm{f}$ & $0,407 \pm 0,089$ \\
\hline
\end{tabular}

Kruskal-Walis $\left(^{*}\right) \mathrm{X}^{2}=108,64 ; \mathrm{p}<0,05 ;\left(^{* *}\right) \mathrm{X}^{2}=106,48$; $\mathrm{p}<0,05$; letras diferentes são estatisticamente significantes. ${ }^{* * *}$ ) método segundo ASTM D-2395 (ASTM, 2002). ( ${ }^{* * * *}$ não foi possível a obtenção de corpos de prova homogêneos. ZR: com zona de reação e sadio, EXS: com acúmulo de extrativos, NS: normal e sadio, $\mathrm{PB}_{\mathrm{INC}}$ : com podridão branca incipiente, $\mathrm{PM}_{\mathrm{INT}}$ : com podridão mole intensa, $\mathrm{PB}_{\mathrm{INT}}$ : com podridão branca intensa.

depositados no lume e na parede das células do lenho de tipuana e evidenciados por análises macro e microscópicas (BRAZOLIN, 2009). Os extrativos do lenho podem conferir maior tensão de ruptura mecânica ou estabilidade dimensional (DADSWELL; HILLIS, 1962) e aumentar os valores de densidade do lenho (TOMAZELLO-FILHO et al., 2008).

O lenho normal-sadio (NS) apresentou valores de módulo de ruptura e módulo de elasticidade de 62 e 4642 $\mathrm{MPa}$, significativamente superiores aos dos lenhos afetados pelos fungos de podridão branca e mole. No entanto, a literatura reporta valores de $83,5 \mathrm{MPa}$ para o módulo de ruptura e de $8506 \mathrm{MPa}$ para a módulo de elasticidade, no lenho de tipuana (MAINIERI; CHIMELO, 1989).

Os padrões de biodeterioração do lenho com podridão branca e mole $\left(\mathrm{PB}_{\mathrm{INC}} ; \mathrm{PM}_{\mathrm{INT}} ; \mathrm{PB}_{\mathrm{INT}}\right)$ apresentaram os menores e significativos valores de módulo de ruptura e módulo de elasticidade; destaque para podridão branca intensa $\left(\mathrm{PB}_{\mathrm{INT}}\right)$, com valores de 5 e $571 \mathrm{MPa}$ para o módulo de ruptura e módulo de elasticidade do lenho, respectivamente. As reduções dos valores do módulo de ruptura e de módulo de elasticidade estão relacionadas às alterações da parede celular das células do lenho de tipuana pelos fungos de podridão branca (BRAZOLIN, 2009).

A redução nas propriedades mecânicas observada no lenho de tipuana afetado pelos fungos xilófagos em comparação com o normal-sadio (NS) foi significativa. No estágio incipiente de biodeterioração do lenho de tipuana, observou-se que a discreta alteração macroscópica de coloração resulta em uma significativa perda de 55\% do módulo de ruptura, atingindo $79-93 \%$ em estágio avançado do apodrecimento do lenho. Essa relação entre biodeterioração e redução significativa da tensão de ruptura mecânica foi observada no lenho de ash (Fraxinus excelsior) nos estágios iniciais de biodeterioração pelo fungo de podridão branca Inonotus hispidus (YOUNG, 1984) e de outras espécies de folhosas afetados por diversos fungos xilófagos (BODIG; JAYNE, 1992; EATON; HALE, 1993; TANAKA, 1991; TOMAZELLO-FILHO et al., 2008).

Portanto, a existência de regiões do lenho das árvores urbanas, com sintomas de biodeterioração incipiente, deve ser considerada no diagnóstico do risco de queda, pela redução significativa da tensão de ruptura mecânica. Destaca-se que o lenho de folhosas é mais comumente afetado por fungos de podridão branca, em relação à mole, considerada importante no processo de sucessão de organismos deterioradores do lenho do que no risco de ruptura do tronco das árvores (MATTHECK; KUBLER, 1995).

A variação dos valores de módulo de ruptura e do módulo de elasticidade do lenho de tipuana, em relação a sua densidade aparente, obtida com base na ASTM D-2395

Cerne, Lavras, v. 20, n. 2, p. 183-190, abr./jun. 2014 

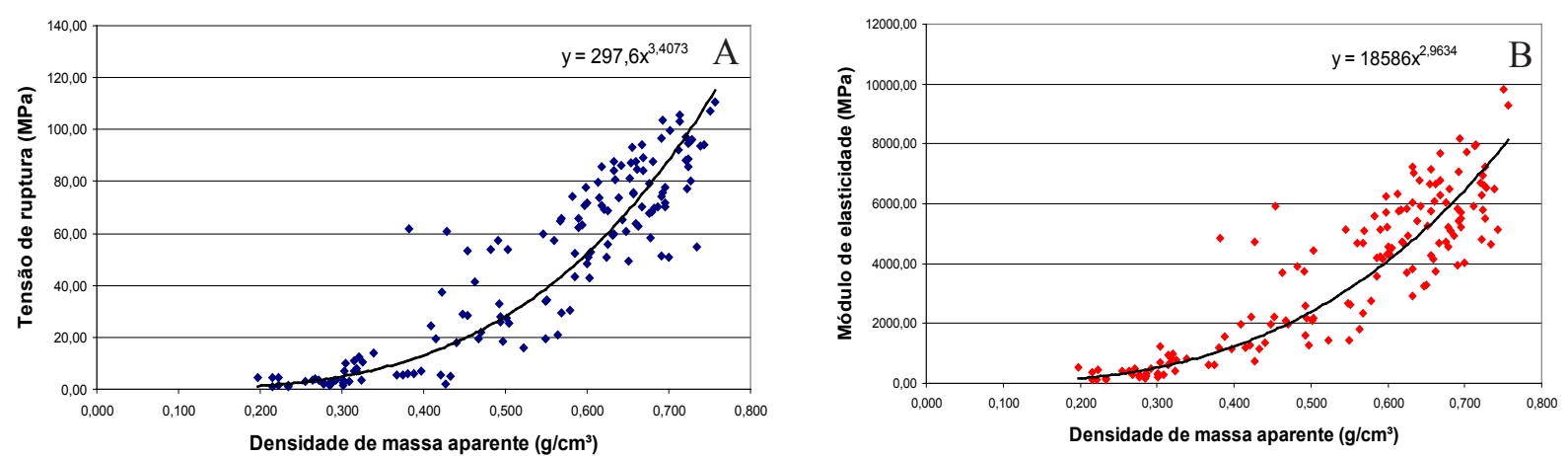

Figura 2 - Variação do módulo de ruptura (A) e do módulo de elasticidade (B) do lenho de tipuana em relação aos valores de densidades de diferentes padrões de biodeterioração.

Figure 2 - Variation of modulus of rupture $(A)$ and of elasticity modulus $(B)$ of the wood of tipuana trees in relation to the values of densities of different patterns of biodeterioration.

(ASTM, 2002), em diferentes estágios de biodeterioração e ajustaram-se aos modelos de potência, com coeficientes de determinação $\left(R^{2}\right)$ de 0,86 e 0,77 , respectivamente, com correlações positivas (Figura 2). Esses modelos, na prática, permitem estimar as propriedades mecânicas do lenho de tipuana com os valores de densidade aparente do lenho sadio ou apodrecido. Da mesma forma, permite inferir com maior precisão a resistência do lenho aos esforços exercidos pelo vento e pela massa própria por cálculos estruturais em modelos estáticos ou dinâmicos.

Nos ensaios de flexão, o modelo de falha do lenho normal e biodeteriorado relacionaram-se com o tipo de podridão, com $100 \%$ dos corpos de prova do lenho afetados por podridão mole, rompendo por tração abrupta e $66 \%$ com podridão branca por tração simples. De acordo com Brazolin (2009), o lenho de tipuana afetado por podridão mole é mais friável pela depleção da celulose, formando cavidades na camada $S_{2}$ da parede celular secundária, permanecendo a lignina residual. No lenho afetado por podridão branca, os canais de erosão na parede das fibras induzem maior susceptibilidade à ruptura por tração simples. Os modelos de falha observados nos corpos de prova do lenho foram, da mesma forma, associados às alterações na estrutura molecular das células por Bodig e Jayne (1993) e Mattheck e Kubler (1995).

\section{CONCLUSÕES}

Na caracterização físico-mecânica do lenho de tipuana, foram classificados sete padrões de biodeterioração pelo perfil radial de densidade por densitometria de raios $\mathrm{X}$.

Os ensaios mecânicos do lenho mostraram correlação entre os valores de resistência e rigidez com os padrões de biodeterioração.

A redução da densidade, resistência e de rigidez relacionou-se com a intensidade de biodeterioração do lenho, com implicação na avaliação do risco de queda das árvores de tipuana em área urbana.

\section{REFERÊNCIAS}

AMARAL, A. C. B.; TOMAZELLO FILHO, M. Avaliação das características dos anéis de crescimento de Pinus taeda pela técnica de microdensitometria de raios X. Revista Ciência e Tecnologia, Piracicaba, v. 6, n. 11/12, p. 17-23, 1998.

\section{AMERICAN SOCIETY OF TESTING MATERIALS. D-2395-02: standard test method for specific gravity of wood and wood-base materials. West Conshohocken, 2002. 9 p.}

\section{ASSOCIAÇÃO BRASILEIRA DE NORMAS}

TÉCNICAS. NBR 7190: projeto de estruturas de madeira: anexo $\mathrm{B}$, determinação das propriedades das madeiras para projetos de estruturas. Rio de Janeiro, 1997. $107 \mathrm{p}$.

BODIG, J.; JAYNE, B. A. Mechanics of wood and wood composites. 2 ed. New York: V. N. Reinhold, 1992. $721 \mathrm{p}$.

Cerne, Lavras, v. 20, n. 2, p. 183-190, abr./jun. 2014 
BRAZOLIN, S. Biodeterioração, anatomia do lenho e análise de risco de queda de árvores de tipuana, Tipuana tipu (Benth.) O. Kuntze, nos passeios públicos da cidade de São Paulo, SP. 2009. 267 p. Dissertação (Mestrado em Recursos Florestais) - Escola Superior de Agricultura "Luiz de Queiroz", Piracicaba, 2009.

BRAZOLIN, S.; AMARAL, R. D. A. M.; TOMAZELLO-FILHO, M. Ocorrência de organismos xilófagos em árvores de Tipuana tipu (Benth.) Kuntze da cidade de São Paulo, SP. In: SIMPÓSIO DE PÓSGRADUAÇÃO EM CIÊNCIAS FLORESTAIS, 4., 2006, Piracicaba. Anais... Piracicaba: ESALQ, 2006. 1 CD-ROM.

BUCUR, V.; GARROS, S.; NAVARRETE, A.; TROYA, T. de; GUYONET, R. Kinetics of wood degradation by fungi with X-ray microdensitometric technique. Wood Science and Technology, Reading, v. 31, p. 383-389, 1997.

COSTA-LEONARDO, A. M. Cupins-praga: morfologia, biologia e controle. Rio Claro: EDIFURB, 2002. 128 p.

DADSWELL, H. E.; HILLIS, W. E. Wood. In: HILLIS, W. E. (Ed.). Wood extractives. London: Academic, 1962. p. 3-49.

EATON, R. A.; HALE, M. D. C. Wood: decay, pests and protection. London: Chapman \& Hal, 1993. 546 p.

MACCHIONI, N.; PALANTI, S.; ROZENBERG, P. Measurements of fungal wood decay on Scots pine and beech by means on X-ray microdensitometry. Wood Science and Technology, Reading, v. 41, p. 417-426, 2007.

MAINIERI, C.; CHIMELO, J. P. Fichas das características das madeiras brasileiras. São Paulo: IPT, 1989. $432 \mathrm{p}$.

MATTHECK, C.; KUBLER, H. Wood: the internal optimization of trees. New York: Springer-Verlag, 1995. 129 p. (Springer Series in Wood).

ROMAGNANO, L. F. T. D. Instrumentos de gestão ambiental integrada: diretrizes para o controle de

Cerne, Lavras, v. 20, n. 2, p. 183-190, abr./jun. 2014 cupins-subterrâneos em ambientes construídos. 2004. 126 p. Dissertação (Mestrado em Tecnologia Ambiental) - Instituto de Pesquisas Tecnológicas do Estado de São Paulo, São Paulo, 2004.

SÃO PAULO. Secretaria Municipal do Verde e do Meio Ambiente. GEO cidade de São Paulo: panorama do meio ambiente urbano. São Paulo, 2004. 204 p.

TANAKA, T. Evaluation of bending strenght by nonstrenght methods of Ezomatzu with white pocket rot. In: ANNUAL MEETING OF IRG-WP, 22., 1991, Stockholm. Proceedings... Stockholm: The International Research Group on Wood Preservation, 1991. (Doc. IRG/WP/2371). 1 CD-ROM.

TOLEDO, S. R. G.; ROMAGNANO, L. F. T. D. Distribuição e ocorrência de cupim-subterrâneo Coptotermes gestroi em árvores urbanas no município de São Paulo, Pacaembu. In: CONGRESSO BRASILEIRO DE ZOOLOGIA, 16., 2006, Londrina. Resumos... Londrina: UEL, 2006. 1 CD-ROM.

TOMAZELLO FILHO, M.; BRAZOLIN, S.; CHAGAS, M. P. Application of X-ray technique in nondestructive evaluation of eucalypt wood. Maderas, Ciencia y Tecnologia, Concepción, v. 10, n. 2, p. 139-149, 2008.

YOUNG, C. W. T. The external signs of decay in trees. London: Department of the Environmental, 1984. 11 p. (Arboricultural Leaflet, 1).

Recebido: 13 de dezembro de 2010; aceito: 23 de agosto de 2013. 